and D. George (eds.)

\title{
New species and records of deep-water Cirratulidae (Polychaeta) from off Northern California
}

\author{
JAMES A. BLAKE \\ ENSR Marine and Coastal Center, 89 Water Street. Woods Hole, Massachusetts 02543 USA. \\ E-mail: jblake@ensr.aecom.com
}

\begin{abstract}
SUMMARY: Polychaetes of the family Cirratulidae are among the most important macrofaunal invertebrates in deep-sea benthic communities off northern California. The genus Chaetozone includes several species that are among the dominant species in depths of 2400-3200 m. Four of the most common species of Chaetozone are described in this paper. Of these four species, only C. spinosa Moore, 1903 has been previously described. Three other species are new to science. C. brunnea, $\mathrm{n}$. sp. has a short, triangular-shaped prostomium, brown body colour, and an enlarged "stomach" which distends the body in a characteristic pattern. C.allanotai, n. sp. has a unique methyl green staining pattern that provides a means to readily identify juveniles and fragmented adults. A third new species, C. palaea, n. sp has posterior spines that are unusually broad, providing a spectacular armature. These species are compared with the type species, $C$. setosa from the Arctic. New details concerning segmentation of the anterior end, morphology of the nuchal organs, and posterior spines, represent a suite of characters that, in combination, will be used in a phylogenetic analysis of cirratulid polychaetes.
\end{abstract}

Keywords: Polychaeta, Cirratulidae, Chaetozone, California, deep-sea benthos.

RESUMEN: NUEVAS ESPECIES Y CITAS DE CIRRATÚLIDOS DE AGUAS PROFUNDAS (ANNELIDA: CiRRATULIDAE) ENFRENTE A LAS COSTAS DEL NORTE DE CALIFORNIA. - Los poliquetos de la familia Cirratulidae se encuentran entre los invertebrados macrofaunales más importantes de las comunidades bentónicas de aguas profundas del Norte de California. El género Chaetozone incluye varias especies que se encuentran entre las dominantes entre los 2400-3200 m de profundidad. En este trabajo se describen cuatro de las especies más importantes del genero Chaetozone. De estas cuatro especies, únicamente C. spinosa Moore ha sido previamente descrita. Las otras tres especies son nuevas para la ciencia. C. brunnea, n. sp. tiene prostomio corto, triangular, cuerpo de color marrón, y un "estómago" dilatado que distiende el cuerpo dándole una forma característica. $C$. allanotai, n. sp. presenta un patron de tinción con Verde de Metilo único, que proporciona un medio para la fácil identificación de juveniles y fragmentos de adultos. Una tercera nueva especie, $C$. palaea, n. sp. tiene espinas posteriores inusualmente anchas, lo que le proporcionan una espectacular armadura. Estas especies se comparan con la especies tipo, $C$. setosa del Ártico. Los detalles relacionados con el extremo anterior, la morfología de los órganos nuchales, y las espinas posteriores representan nuevos caracteres que serán utilizados en un análisis filogenético de los poliquetos cirratúlidos.

Palabras clave: Polychaeta, Cirratulidae, Chaetozone, California, benthos de profundidad.

\section{INTRODUCTION}

The Cirratulidae are one of the dominant infaunal polychaete families in continental slope sediments off northern California. As part of extensive reconnaissance surveys off San Francisco and vicinity in 1990-1991 to identify potential deep-water disposal sites for dredged material, a total of 25 species of Cirratulidae in five genera were identified. Since 1996, monitoring of the San Francisco Deep-Ocean Disposal Site (SF-DODS) off the Farallon Islands has consistently yielded 14-16 cirratulid species on an annual basis with additional new and rare taxa continuing to be discovered. Most of the taxa from these two programmes are in the genera Chaetozone (8-10 species) and Aphelochaeta 
(10-12 species). Four species of Monticellina are limited to upper slope depths; another rare species occurs on the lower slope. Two species of Tharyx, including T. kirkegaardi Blake, 1991 and one new species, have been found together with several specimens of Cirriformia. The genus Caulleriella is not present in these deep-water collections. These results complement the monograph of Blake (1996) who described and illustrated 46 species in eight genera from the northeastern Pacific, mostly from shelf depths and the intertidal zone of California.

The present paper deals with some characteristic species of Chaetozone from the original baseline surveys of 1991 and the more recent SF-DODS monitoring survey collections. Among the species of Chaetozone, only one, C. spinosa Moore, 1903, is well described in the literature (Blake, 1996) and additional information on its morphology is presented here. Chaetozone spinosa and two undescribed Chaetozone species are very common and often recorded among the most abundant taxa at selected stations currently being monitored in the 2200-3200 $\mathrm{m}$ depth intervals at SF-DODS. Both of the two undescribed species have distinctive morphology making them readily identifiable in benthic collections. Chaetozone brunnea, n. sp. has a short, triangular-shaped prostomium and distinctive brownish coloration on the body which, together with an enlarged "stomach," make this worm easy to distinguish from congeners. Chaetozone allanotai, n. sp. has a unique methyl green staining pattern that provides a means to easily identify juveniles and fragmented adults. A third species, C. palaea, n. sp, is less common yet is one of the most spectacular species of this genus ever encountered. The posterior cinctures consist of spines that are unusually broad and resemble palaea of other polychaetes. Most specimens examined had long natatory-like chaetae. However, there was little evidence of sexual maturity among these specimens. New details concerning segmentation of the anterior end together with morphology of the nuchal organs, posterior spines, and partitioning of the peristomium may be important for phylogenetic analyses of cirratulid polychaetes.

Type specimens of the three new species described in this paper are deposited in the Los Angeles County Museum of Natural History in Los Angeles, California (LACM-AFH Poly) and the National Museum of Natural History, Smithsonian Institution, Washington, D.C. (NMNH). The more extensive bulk collections of these species will eventually be distributed among these same museums and the California Academy of Sciences in San Francisco.

\section{TAXONOMIC ACCOUNT}

Chaetozone brunnea $\mathrm{n}$. $\mathrm{sp}$.

(Figs. 1, 2, 3A-D)

Material examined. California continental slope, San Francisco Deep Ocean Disposal Site (SF-DODS) west of Farallon Islands, September 2003 monitoring survey, R/V Point Sur: Sta. 6, $37^{\circ} 40.08^{`} \mathrm{~N}, 123^{\circ} 32.945^{\prime} \mathrm{W}, 2750 \mathrm{~m}$, 23 Sep 2003, 13 paratypes (USNM 1076965); Sta. 10, 37 $39.996^{\prime} \mathrm{N}, 123^{\circ} 30.976^{\prime} \mathrm{W}, 2736 \mathrm{~m}$, 26 Sep 2003, 37 paratypes (LACM-AHF Poly 2159); Sta. 64, $37^{\circ} 35.981^{\prime} \mathrm{N}, 123^{\circ} 32.958^{\prime} \mathrm{W}, 3130 \mathrm{~m}, 26$ Sep 2003,15 paratypes (LACM-AHF Poly 2160); Sta. 92, 3704.998 N, $123^{\circ} 34.979^{\prime} \mathrm{W}$, 2850 m, 23 Sep 2003, 16 paratypes (LACM-AHF Poly 2161); Sta. $108,37^{\circ} 38.954^{\prime} \mathrm{N}, 123^{\circ} 24.936^{\prime} \mathrm{W}, 2670 \mathrm{~m}, 26$ Sep 2003 , holotype (LACM-AHF Poly 2162), 9 paratypes (LACM-AHF Poly 2163).Off San Francisco, north side of Pioneer Canyon, Area 3, U.S. EPA 102 Site Survey, September 1991, R/V Point Sur: Sta. 3-18, $37^{\circ} 22.31^{\top} \mathrm{N}, 123^{\circ} 19.24^{\top} \mathrm{W}, 1990 \mathrm{~m}, 25$ Sep 1991,1 specimen (ENSR voucher collection).-Additional SF-DODS specimens set aside for SEM analysis: Sta. $17,37^{\circ} 38.013^{`} \mathrm{~N}, 123^{\circ} 27.944^{`} \mathrm{~W}, 2775$ m, 21 Sep 2002, 3 specimens.

Description. A small to moderately-sized species, $6.0 \mathrm{~mm}$ long, $0.5 \mathrm{~mm}$ wide across posterior of thorax, with 45-55 chaetigers. Body with distinctive shape, including anterior thoracic region of about 20 short, narrow chaetigers, an enlarged and darkly pigmented "stomach" area, followed by a narrow abdominal region dominated by moniliform cinctured segments as wide as long and containing spherical fecal pellets (Figs. 1, 3A). Body with distinctive brown pigment over most of body, but most evident in anterior chaetigers. Prostomium tapering anteriorly to rounded tip, as wide as long, lacking eyes (Figs. 2A-B, 3B); nuchal organs oval, sometimes everted with cilia prominent, located dorsal to posterior edge of oral lips (Fig. 2A). Peristomium with one prominent partition separating it from prostomium (Fig. 2A); posterior dorsal lobe of peristomium extends over achaetous segment 1 carrying dorsal tentacles posteriorly over same segment (Fig. 2A). First pair of branchiae posterior to tentacles on achaetous segment 1; subsequent branchiae dorsal to notochaetae on each anterior chaetiger (Fig. 2A). Anterior chaetae all capillaries; many specimens with long, natatory chaetae as well as normal capillaries (Fig. 3B). Dorsal and ventral spines from about chaetigers 30-35, initially as long, spinous capillaries, then becoming broad, blunt-tipped spines accompanied by long, thin, sharply-pointed spines (Figs. 2C-E, 3D); short spines number 7-8 in 


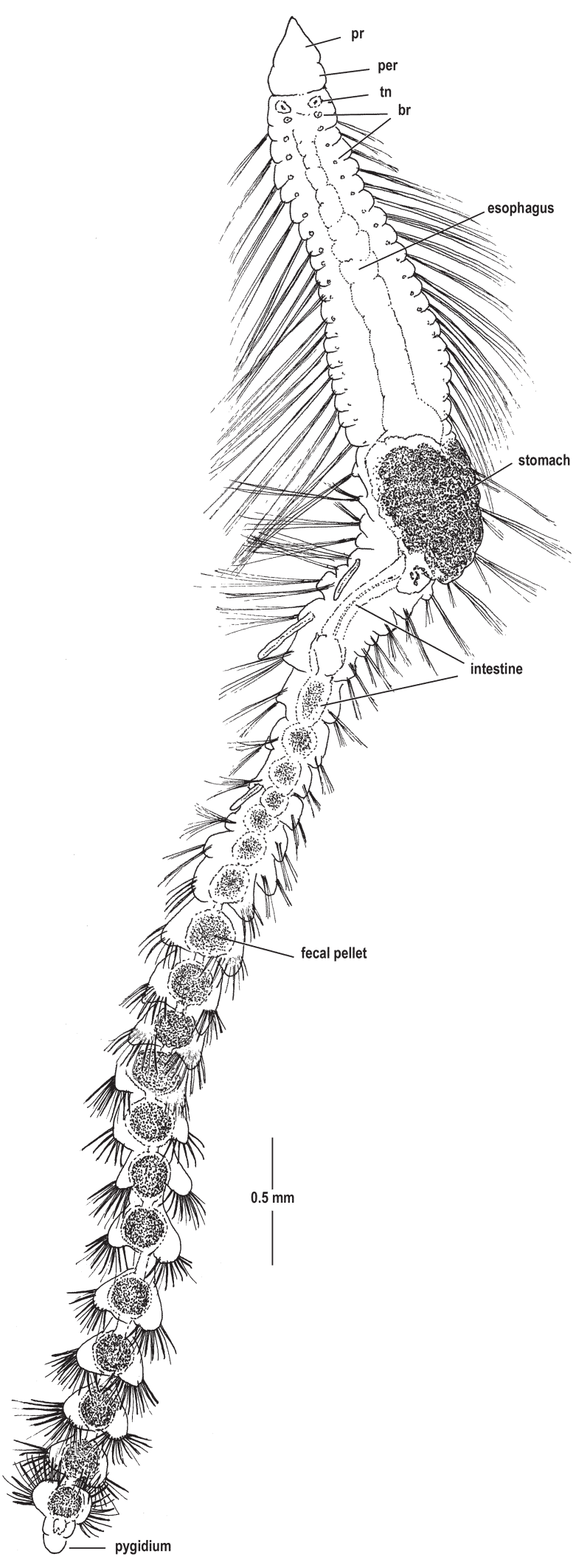

FIG. 1. - Chaetozone brunnea, n. sp. (Holotype, SF-DODS Sta. 108, LACM-AHF Poly 2162). Entire animal in dorsal view. Abbreviations: br, branchiae; per, peristomium; pr, prostomium; tn, tentacle. notopodia and 9-10 in neuropodia; cinctures complete (Fig. 3C), but with narrow dorsal, ventral, and lateral gaps separating chaetal fascicles (Figs. 2C, $5 \mathrm{C})$. Individual spines sometimes with internal striae (Fig. 2D). Pygidium a simple disk (Figs. 1, 3A). No distinctive methyl green staining pattern.

Etymology. The epithet "brunnea" is from the Medieval Latin brunneus, referring to the distinctive brown coloration of this species.

Remarks. The unusual body shape denoted by the enlarged and often dark mid-body stomach and distinctive brown pigmentation characterize Chaetozone brunnea. No other described species of Chaetozone has these characteristics. The posterior spines form well-developed cinctures, but they are open dorsally, ventrally, and laterally. The companion chaetae in posterior cinctures are thicker than in related species and often appear as spinous chaetae rather than true capillaries. An undescribed species from deep-water off Antarctica appears to be very closely related to $C$. brunnea. The Antarctic species is larger, but has a similar anterior region with an achaetous segment (over which lies the peristomial tentacles) and bears the first pair of branchiae; the second pair of branchiae occurs on chaetiger 1 . This species also has a brownish body coloration with the borders of individual segments lined with melanin. This pigment pattern is more defined than in $C$. brunnea. The arrangement of the posterior spines is similar to C. brunnea, but the companion chaetae are thinner. The Antarctic species has a longer and narrower prostomium and the enlarged "stomach" is more posterior on the body and occupies several segments. The Antarctic species will be described in a forthcoming paper on Antarctic deep-water Cirratulidae (Blake, in preparation).

Ecology. Chaetozone brunnea is a characteristic component of benthic assemblages along lower slope depths composed of very fine grain sediments on the northern California continental slope. In 135 quantitative box cores collected over a 10 -year period from January 1996 to September-October 2004, 1598 specimens of $C$. brunnea were collected which resulted in the species being the tenth most abundant species out of approximately 800 taxa identified over the entire study area. The species was the second most abundant cirratulid overall next to $C$. allanotai. Although present in middle slope depths 


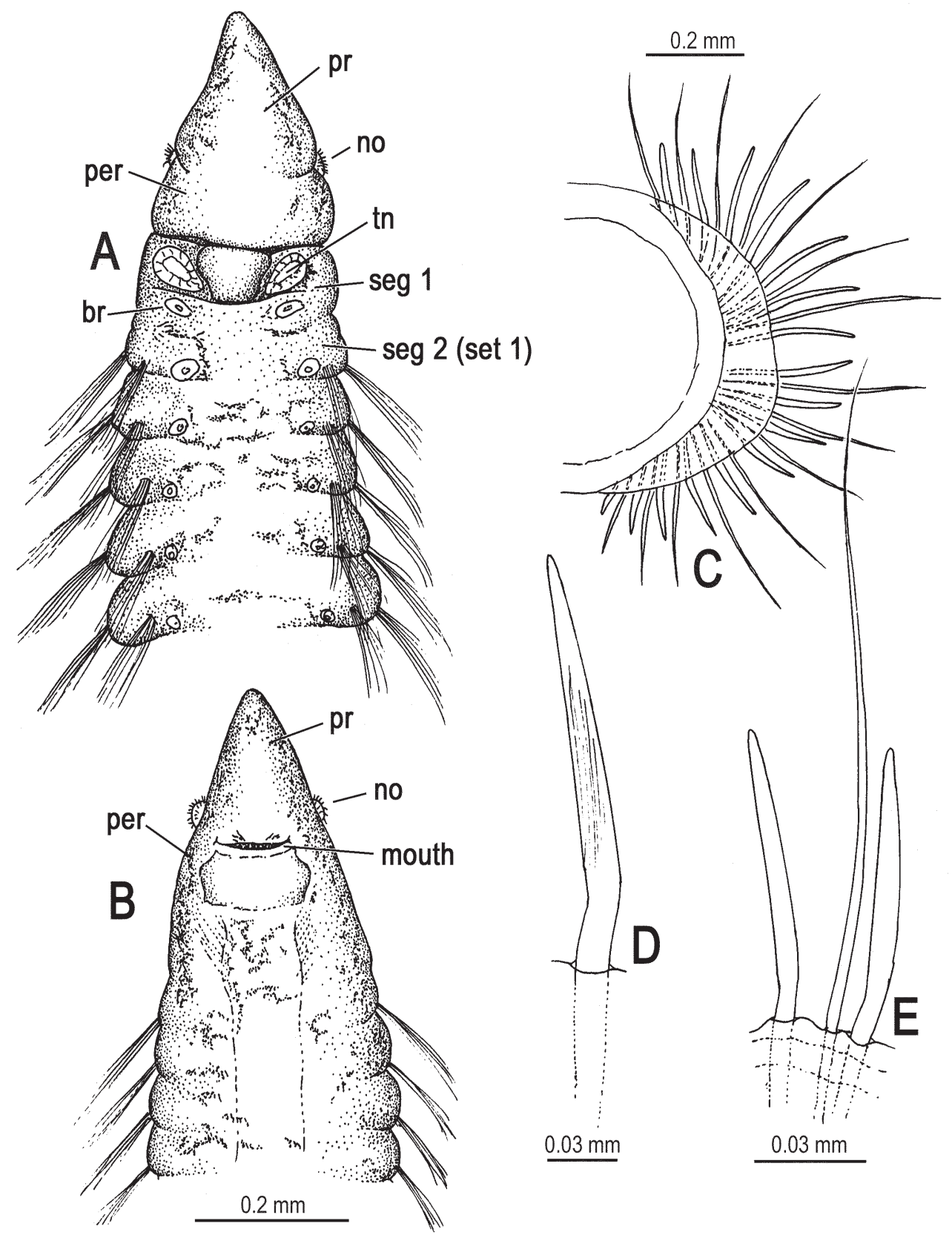

FIG. 2. - Chaetozone brunnea, n. sp. (paratype, SF-DODS Sta. 6, USNM 1076965): A, anterior end, dorsal view; B, same ventral view; C, posterior parapodium, anterior view; D, posterior spine; E, posterior spines and capillary. Abbreviations: br, branchia; no, nuchal organ; per, peristomium; pr, prostomium; seg, segment; tn, tentacle.

from about $2200 \mathrm{~m}$, C. brunnea becomes a dominant taxon at 2850-3150 m. Other deep-water polychaetes characterizing these sediments and occurring with $C$. brunnea are Neonotomastus glabrus Fauchald, 1972 (Capitellidae), Prionospio delta Hartman, 1965 (Spionidae), Levinsenia flava Strelsov, 1973 (Paraonidae), and another cirratulid C. spinosa (Moore, 1905). An undescribed aplacophoran, Claviderma sp. B is also characteristic of this assemblage.
Distribution. A characteristic species of middle and lower slope depths off northern California, ca. 2000-3200 m.

\section{Chaetozone palaea $\mathrm{n}$. $\mathrm{sp}$.}

(Figs. 3E-I, 4)

Material examined. California, continental slope off San Francisco, U.S. Navy 103 Site Survey, July 1991, R/V Wecoma: Sta. B-6, $37^{\circ} 38.78^{\prime} \mathrm{N}, 123^{\circ} 25.21^{\prime} \mathrm{W}, 2720 \mathrm{~m}, 21$ Jul 1991, paratype (LACM-

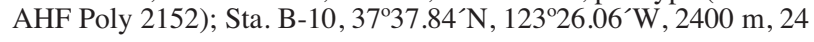




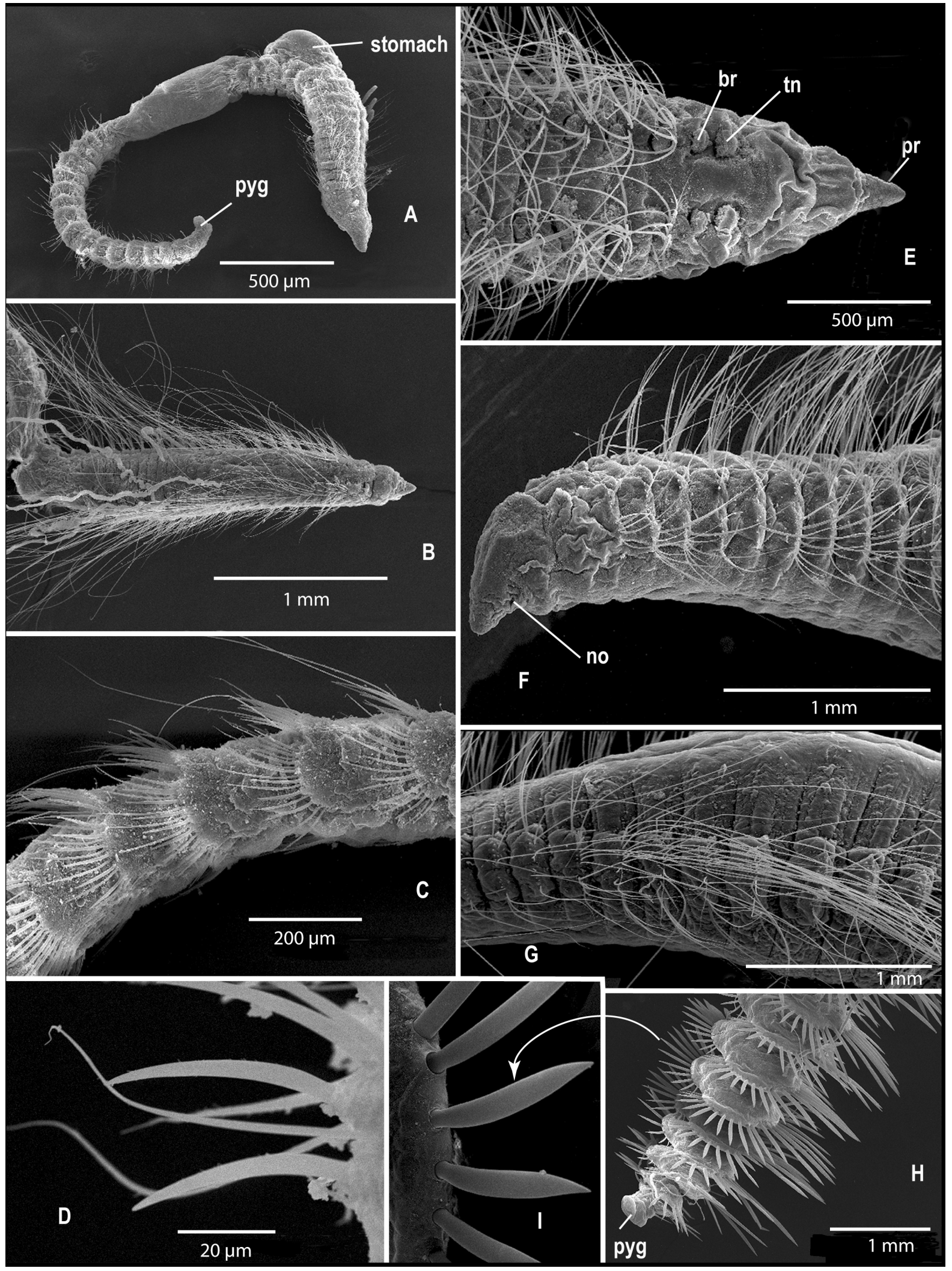

FIG. 3. - Chaetozone brunnea, n.sp. (SF-DODS Sta. 17, Sep 2002): A, entire animal in dorso-lateral view; B, anterior end of another specimen in dorsal view; $\mathrm{C}$, section of posterior end showing cinctures of spines; D, posterior spines and capillaries. Chaetozone palaea (SFDODS Sta. 50, Sep 2002): E, anterior end, dorsal view; F, anterior of another specimen, lateral view; G, expanded posterior thoracic region, lateral view; $\mathrm{H}$, posterior segments showing chaetal cinctures and pygidium, ventral view; I, individual posterior spines (not to scale). Abbreviations: br, branchia; no, nuchal organ; pyg, pygidium; pr, prostomium; tn, tentacle. 


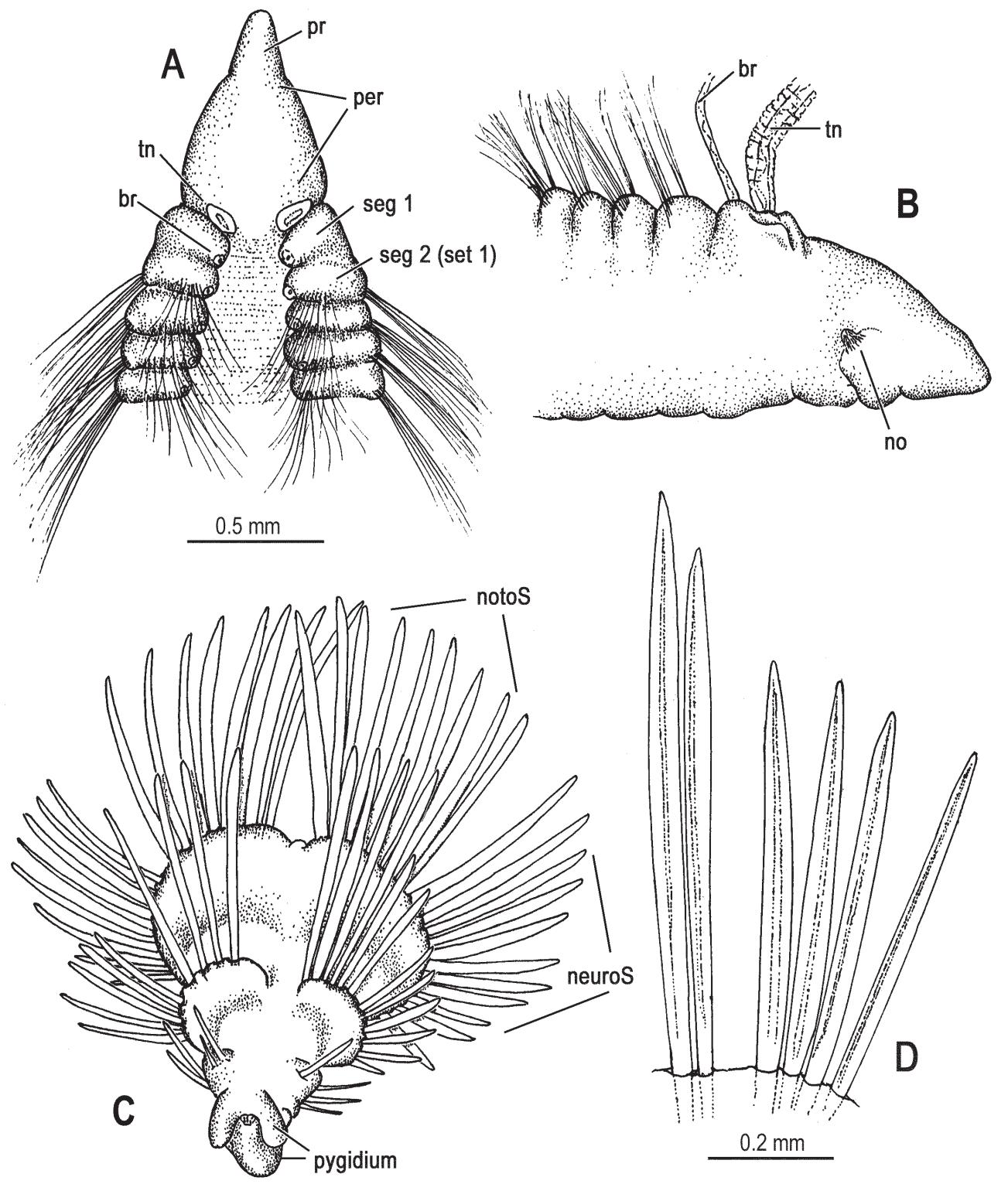

FIG. 4. - Chaetozone palaea, n. sp. (SF-DODS Sta. 6, ENSR collections): A, anterior end, dorsal view; B, another specimen, lateral view; C, posterior end, posterior-dorsal view showing chaetal cinctures and pygidum; D, posterior spines. Abbreviations: br, branchia; no, nuchal organ; notoS, notochaetae; neuroS, neurochaetae; per, peristomium; pr, prostomium; seg, segment; tn, tentacle.

Jul 1991, paratype (LACM-AHF Poly 2153); Sta. B-22, $37^{\circ} 31.75^{\prime} \mathrm{N}, 123^{\circ} 17.95^{`} \mathrm{~W}, 2045 \mathrm{~m}, 25 \mathrm{Jul} 1991,2$ paratypes (LACM-AHF Poly 2154).-Off San Francisco, north side of Pioneer Canyon, Area 3, U.S. EPA 102 Site Survey, September

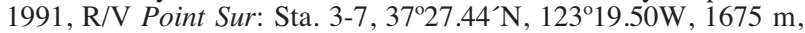
Sep 14, 1991, paratype (LACM-AHF Poly 2155); Sta. 3-8, $37^{\circ} 27.13^{\prime} \mathrm{N}, 123^{\circ} 23.02^{\prime} \mathrm{W}, 2005 \mathrm{~m}, 13$ Sep 1991,3 paratypes (LACM-AHF Poly 2156); Sta. 3-12, $37^{\circ} 25.03^{\prime} \mathrm{N}, 123^{\circ} 18.00^{\prime} \mathrm{W}$, $1745 \mathrm{~m}, 15$ Sep 1991, Holotype (LACM-AHF Poly 2157); Sta. 3$13,37^{\circ} 24,30^{\prime} \mathrm{N}, 1223^{\circ} 20.02^{\prime} \mathrm{W}, 1780 \mathrm{~m}, 15 \mathrm{Sep} 1991,2$ paratypes (LACM-AHF Poly 2158); Sta. 3-18, $37^{\circ} 22.31^{\prime} \mathrm{N}, 123^{\circ} 19.24^{\prime} \mathrm{W}$, 1990 m, 25 Sep 1991, paratype (USNM 1076959).-Off San Francisco, Pioneer Canyon, U.S. EPA 102 Site Survey, September 1991, R/V Point Sur: Sta. C-5, 37017,91`N, 123⒔50`W, 2065 m, 19 Sep 1991, paratype (USNM 1076960)._-Off San Francisco, south side of Pioneer Canyon, Area 4, U.S. EPA 102 Site Survey, September 1991, R/V Point Sur: Sta. 4-5, 37013.54' N, $123^{\circ} 16.26^{`} \mathrm{~W}, 1820 \mathrm{~m}, 17 \mathrm{Sep} 1991,2$ paratypes (USNM 1076961); Sta. 4-6, 37 $14.03^{\prime} \mathrm{N}, 123^{\circ} 16.84^{\prime} \mathrm{W}, 2020 \mathrm{~m}, 17$ Sep 1991, 2 paratypes (USNM 1076962); Sta. 4-11, $37^{\circ} 10.14^{`} \mathrm{~N}, 123^{\circ} 16.61^{\prime} \mathrm{W}$,
1970 m, 17 Sep 1991, paratype (USNM 1076963); Sta. 4-15, $37^{\circ} 12.42^{`} \mathrm{~N}, 123^{\circ} 15.81^{\prime} \mathrm{W}, 1730 \mathrm{~m}, 19$ Sep 1991 , paratype (USNM

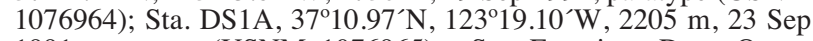
1991, paratype (USNM 1076965). - San Francisco Deep Ocean Disposal Site (SF-DODS) west of Farallon Islands: Sta. 7, $37^{\circ} 40.00^{`} \mathrm{~N}, 123^{\circ} 28,00^{\prime} \mathrm{W}, 2760 \mathrm{~m}$, Oct 1999,11 specimens (ENSR voucher collection); Sta. 16, 37 $38.01^{\prime} \mathrm{N}, 123^{\circ} 26.989^{\prime} \mathrm{N}, 2694 \mathrm{~m}$, Sep 2003, 1 specimen (ENSR voucher collection); Sta. 33, $37^{\circ} 42.00^{\prime} \mathrm{N}, 123^{\circ} 27.00^{\prime} \mathrm{W}, 2425 \mathrm{~m}$, Oct 2000,6 specimens (ENSR voucher collection); Sta. $50,37^{\circ} 42.951^{\prime} \mathrm{N}, 123^{\circ} 25.896^{\prime} \mathrm{W}, 2160 \mathrm{~m}$,

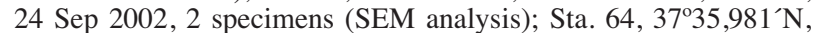
$123^{\circ} 32.958^{\prime} \mathrm{W}, 3130 \mathrm{~m}, 26 \mathrm{Sep} 2003,1$ specimen (ENSR voucher collection); Sta. $114,37^{\circ} 35.084^{\prime} \mathrm{N}, 123^{\circ} 26.964^{\prime} \mathrm{W}, 2420 \mathrm{~m}, 2$ specimens (SEM analysis).

Description. A large species, up to $2.5 \mathrm{~cm}$ long, $2.0 \mathrm{~mm}$ wide across thorax, with about 60 chaetigers. Thoracic region of 13-15 narrow 
chaetigers, followed by expanded middle region of 15-20 chaetigers (Fig. 3G), and then with about 25 narrow, heavily cinctured segments. Prostomium short, narrow, tapering to bluntly rounded tip (Figs. 3E-F, 4A ); eyes absent; oval, ciliated nuchal organs present posterior to mouth (Fig. 4B). Peristomium lacking furrows or partitions. Dorsal tentacles at posterior margin of peristomium, immediately anterior to achaetous segment 1 (Figs. 3E, 4A). First pair of branchiae on achaetous segment 1 ; branchiae in same location on following chaetigers, dorsal to notochaetae (Fig. 4A). Anterior chaetae all capillaries; many specimens with long, natatory chaetae (Fig. 3F-G). Dorsal and ventral spines from chaetigers 21-23, with anterior most spines elongated and thickened then transitioning to very broad, pointed spines (Figs. 3H-I, 4D); spines initially accompanied by a few long, thin companion capillaries, these lost by about chaetiger 30 . Posterior cinctures with large, inflated parapodia bearing heavy, broad spines that sometimes overlap one another; companion capillaries or spines entirely absent (Figs. 3H-I, 4B). Pygidium with one ventral lobe and two dorsal lobes (Figs. 3H, 4C). Methyl green staining prostomium, part of peristomium and first 2-3 segments; an unstained area between prostomium and peristomium may be diagnostic.

Etymology. The epithet "palaea" refers to the very broad posterior spines that characterize the species.

Remarks. The smooth peristomium, achaetous first segment bearing branchiae, and highly modified posterior cinctures bearing unusually broad posterior spines entirely lacking companion chaetae are distinctive for $C$. palaea. The posterior cinctures of spines are the most modified such chaetae yet reported for a species of Chaetozone. Chaetozone setosa spines are also modified, but bears long, thin, companion capillaries among the spines of far posterior chaetigers (Table 1).

Distribution. Middle and lower slope off northern California, 1675-3130 m.

Chaetozone allanotai, $\mathrm{n}$. sp.

(Figs. 5, 6 A-D)

Material examined. California continental slope, San Francisco Deep Ocean Disposal Site (SF-DODS) west of Farallon Islands, September 2003 monitoring survey, R/V Point Sur: Sta. 10, $37^{\circ} 39.996^{`} \mathrm{~N}, 123^{\circ} 30.976^{`} \mathrm{~W}, 2736 \mathrm{~m}, 26$ Sep 2003, 20 paratypes (USNM 1076967); Sta. 17, $37^{\circ} 38.049^{\prime} \mathrm{N}, 123^{\circ} 27.941^{\top} \mathrm{W}, 2750 \mathrm{~m}$, 36 paratypes (LACM-AHF Poly 2164); Sta. $27,37^{\circ} 40.915^{\prime} \mathrm{N}$, $123^{\circ} 31.934^{\prime} \mathrm{W}, 2750 \mathrm{~m}, 10$ paratypes (LACM-AHF Poly 2165); Sta. $92,37^{\circ} 44.998^{\prime} \mathrm{N}, 123^{\circ} 34.979^{\prime} \mathrm{W}, 2850 \mathrm{~m}, 23$ Sep 2003, holotype (LACM-AHF Poly 2166), 8 paratypes (LACM-AHF Poly 2167); Sta. $108,37^{\circ} 38.954^{\prime} \mathrm{N}, 123^{\circ} 24.936^{`} \mathrm{~W}, 2670 \mathrm{~m}, 26$ Sep 2003, 17 paratypes (LACM-AHF Poly 2168); Sta. 116, $37^{\circ} 35.081^{\prime} \mathrm{N}, 123^{\circ} 29.062^{\prime} \mathrm{W}, 2730 \mathrm{~m}, 26$ Sep 2003,12 paratypes (LACM-AHF Poly 2169).-Additional SF-DODS specimens examined for SEM analysis: Sta. 10, 37 $39.999^{\prime} \mathrm{N}, 123^{\circ} 31.001^{\prime} \mathrm{W}$, 2739 m, 22 Sep 2002, 3 specimens.

Description. A moderately-sized species, $10 \mathrm{~mm}$ long, $0.5 \mathrm{~mm}$ wide, with about 90 chaetigers. Prostomium triangular, acute on anterior margin, as wide as long (Figs. 5A-B, 6A-B); eyes absent; nuchal organs oval, located at posterior margin (Figs. 5B, 6B). Peristomium with two incomplete lateral grooves sometimes apparent (Figs. 5A-B). Dorsal tentacles at junction of peristomium and first chaetiger (Figs. 5A-B, 6A). First pair of branchiae immediately posterior to dorsal tentacles indicating remnant of first segment fused to chaetiger 1 (segment 2), subsequent branchiae segmental, located on each chaetiger dorsal to notochaetae (Figs. 5A$\mathrm{B}, 6 \mathrm{C})$. Anterior chaetae all simple capillaries; some specimens with long natatory chaetae. Dorsal and ventral spines from chaetigers 65-70; first spines, narrow, broad pointed capillaries; distinct spines forming posterior cinctures arising from thin membranous noto- and neuropodia by about chaetiger 75 (Figs. 5C-D, 6A). Each spine with sharply-pointed tip that curves back and adheres to the shaft, this feature clearly visible in light microscopy (Fig. 5E), not apparent in SEM (Fig. 6D); cinctures complete, with dorsal and ventral spines arising from high membranous chaetal lobes, with chaetae nearly overlapping at mid-dorsal line (Fig. 5C, 6C); with 11-13 dorsal spines and 15-16 ventral spines per ramus; spines alternating with long, narrow companion capillaries. Pygidium a simple disc (Fig. 5C). Methyl green stain forming distinct pattern, with a clear, unstained, arching dorsal band at the posterior margin of prostomium.

Etymology. This species is named after Mr. Allan Ota, U.S. Environmental Protection Agency, San Francisco, for his support of benthic systematic studies at SF-DODS.

Remarks. The curved tip of the posterior spines of $C$. allanotai is diagnostic and similar to those reported for C. commonalis Blake (1996) from California, C. curvata Hartmann-Schröder (1965) 


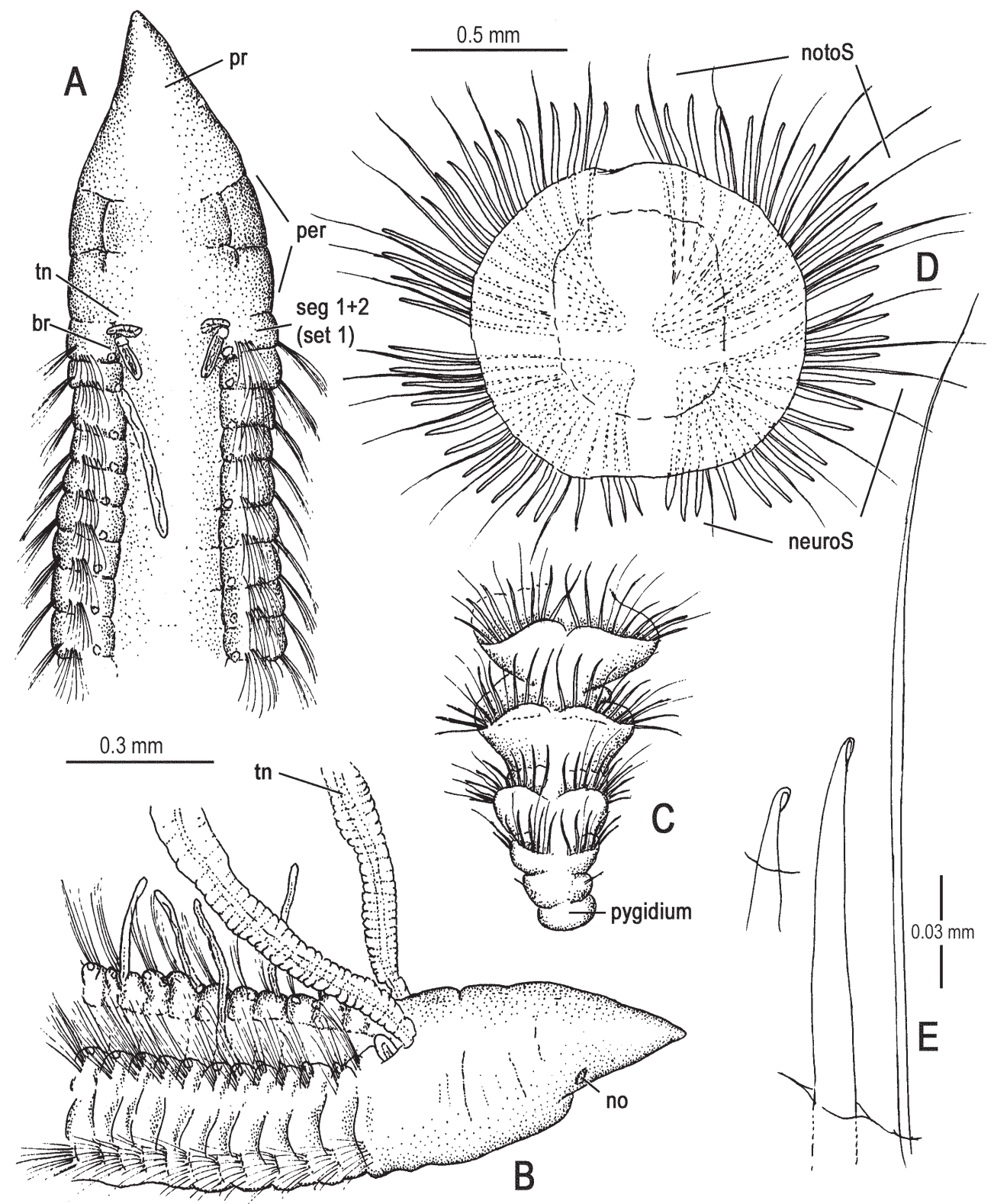

FIG. 5. - Chaetozone allanotai, n. sp. (paratype, SF-DODS, Sta. 108. LACM-AHF Poly 2168): A, anterior end, dorsal view; B, another specimen, lateral view; C, posterior end, dorsal view; D, posterior segment showing arrangement of posterior spines and capillaries; E, posterior spines and capillaries. Abbreviations: br, branchia; no, nuchal organ; notoS, notochaetae; neuroS, neurochaetae; per, peristomium; pr, prostomium; seg, segment; tn, tentacle.

from Chile, and a new species from Massachusetts Bay (See Doner and Blake, 2006). Each of these species is from shelf depths. Chaetozone allanotai differs in the placement of the first pair of branchiae, methyl green staining pattern, and the larger number of spines in posterior chaetigers. In C.allanotai, segment 1 is entirely reduced and fused to chaetigerous segment 2 ; only the branchiae located posterior to the dorsal tentacles denote the presence of segment 1. Chaetozone allanotai together with $C$. spinosa (see below), exhibit the greatest reduction to segment 1 among the species treated in this paper.
On a practical basis, C.allanotai is readily identified among the various cirratulids collected in benthic samples by the characteristic methyl green staining pattern where a clear, unstained band arches up and over the dorsum of the posterior margin of the prostomium. This feature provides a simple method to precisely identify this species even from anterior fragments.

Ecology. Chaetozone allanotai, with 1644 total specimens collected in 135 samples over ten years of sampling (January 1996 to September 2004) is 


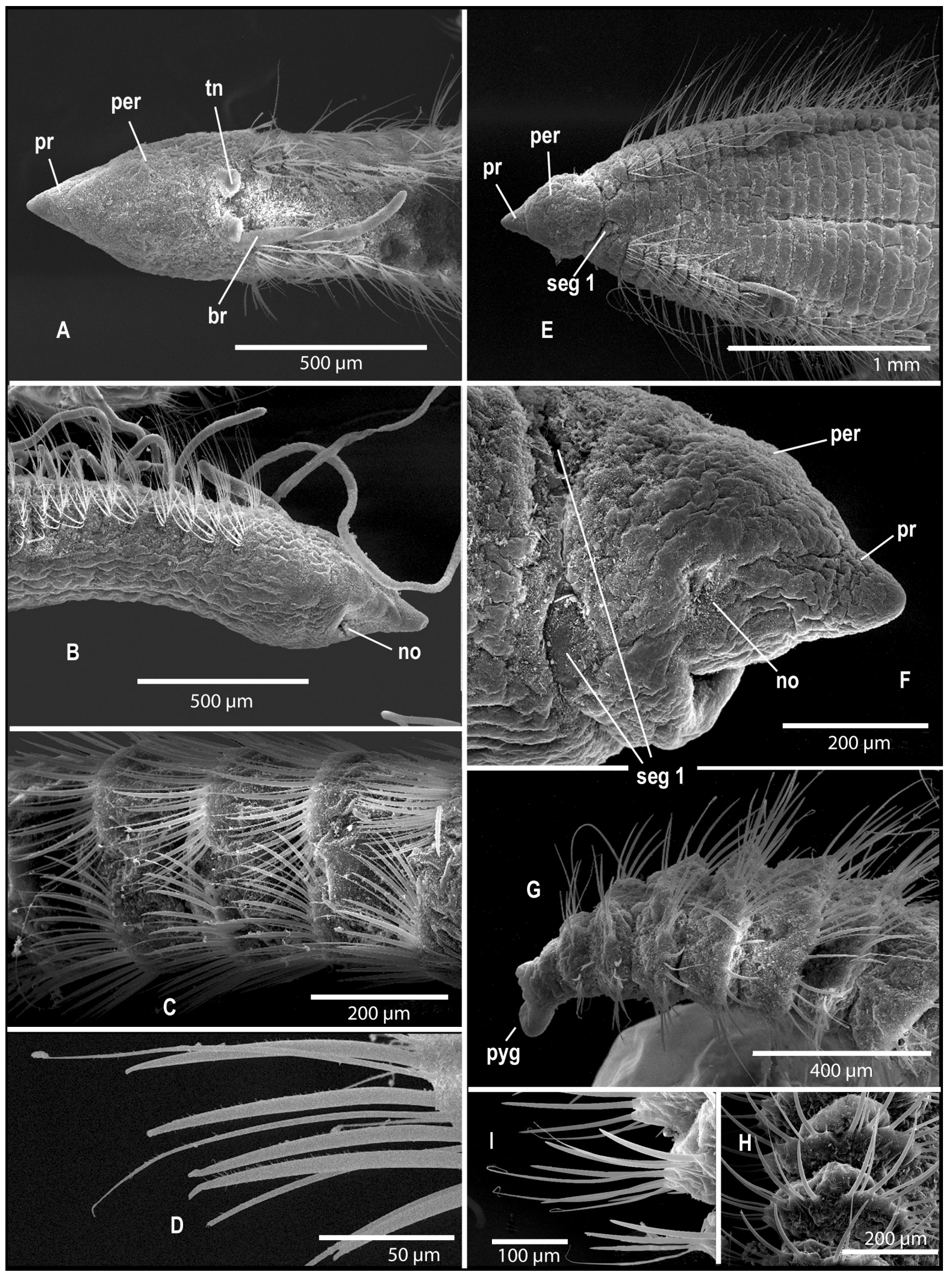

FIG. 6. - Chaetozone allanotai, n. sp. (SF-DODS Sta. 10, Sep 2002): A, anterior end, dorsal view; B, another specimen, ventrolateral view; $\mathrm{C}$, section of posterior chaetigers showing spinous cintures, dorsal view; D, posterior spines. Chaetozone spinosa (SF-DODS Sta. 92, Sep 2002): E, anterior end, dorsal view; F, detail of anterior end of another specimen in lateral view showing nuchal organ and reduced first segment; G, posterior end in lateral view; H, posterior neuropodial spines; I, posterior notopodial spines. Abbreviations: br, branchia; no, nuchal organ; pyg, pygidium; per, peristomium; pr, prostomium; seg, segment; tn, tentacle. 
the most abundant cirratulid species. The species is the ninth most abundant benthic invertebrate from infaunal communities at the SF-DODS disposal site out of approximately 800 species of benthic invertebrates identified to date. Although occurring sympatrically with other abundant species of Chaetozone reported in this paper and ranging over similar depths, C. allanotai is most characteristic of faunal assemblages from approximately 2700-2850 m. Other polychaetes typically occurring with $C$. allanotai are Aricidea simplex Day, 1963 (Paraonidae) and an undescribed paraonid, Aricidea sp. 4. A congener, C. brunnea may also co-occur abundantly with $C$. allanotai.

Distribution. California, in slope depths, 1800$3100 \mathrm{~m}$.

Chaetozone spinosa Moore, 1903

(Fig. 6 E-I)

Chaetozone spinosa Moore, 1903: 468-470, pl. 26, figs. 73-74; Imajima and Hartman, 1964: 297-298; Blake, 1996: 300-303, figs. 8.13-8.14.

Material examined. California continental slope, San Francisco Deep Ocean Disposal Site (SF-DODS) west of Farallon Islands. A total of 686 specimens from nine SF-DODS surveys (1996-2003); the following specimens were set aside for SEM analysis: Sta. 92, $37^{\circ} 44.996^{\prime} \mathrm{N}, 123^{\circ} 34.998^{\prime} \mathrm{W}, 2850 \mathrm{~m}, 3$ specimens; Sta. 13, $37^{\circ} 38.917^{\prime} \mathrm{N}, 123^{\circ} 28.953^{`} \mathrm{~W}, 2902 \mathrm{~m}, 27$ Sep 2002,1 specimen.

Description. A large, robust species, up to 12 $\mathrm{mm}$ long, $0.8 \mathrm{~mm}$ wide, for about 85 chaetigers. Body thickest anteriorly, broadly flattened dorsally (Fig. 6E). Colour in alcohol light tan. Prostomium short, triangular, fused and mostly indistinguishable from peristomium; eyes absent, oval nuchal organs present at posterior margin of prostomium (Fig. 6F); prostomium and peristomium together forming large, heart-shaped head distinctly set off from reduced segment 1 (Fig. 6E-F). Segment 1 seemingly wedged between peristomium and first chaetiger, visible both dorsally and laterally only (Fig. 6F); the first pair of branchiae arise on this reduced segment as apparently do the tentacles. Chaetiger 1 larger than following ones, bearing a pair of branchiae located dorsal to notochaetae. Chaetae of anterior segments broad fascicles of capillaries; long natatory capillaries present on many specimens; both noto- and neurochaetal fascicles of capillaries nearly merging laterally, with little space between; some capillaries with broad yellow blades. Some neurochaetae becoming shorter, forming blunt, acicular spines by chaetigers 21-25; notochaetae also becoming shorter, but retaining sharply-pointed tips until far posterior chaetigers; spines and capillaries of far posterior segments formed into partial cinctures (Fig. 6G-H); spines accompanied by thin capillaries (Fig. 6H-I). Pygidium forming a cupped ventral lobe (Fig. 6G).

Remarks. Use of the SEM allows some refinement of the description provided by Blake (1996). In the 1996 description, a groove or notch between the peristomium and first chaetiger was identified as the location of the tentacles, with the first pair of branchiae stated to be on chaetiger 1 . In fact, the "groove" is actually a reduced segment that can be readily seen dorsally and laterally in the SEMs. The tentacles and first pair of branchiae appear to be associated with this reduced segment. Identification of the reduced segment agrees with findings for other species of Chaetozone where the first segment may be fully intact to more or less completely reduced. The SEMs also confirm structure of the pygidium, the location and shape of nuchal organs, and provide details about the nature of the posterior spines and modified parapodia.

Ecology. From 135 samples collected from the SF-DODS study area over ten years (January 1996 to September 2004), C. spinosa with 772 specimens is the eighteenth most abundant benthic invertebrate species identified to date. The species occurs in very fine sediments and is considerably larger and more robust than either $C$. brunnea or $C$. allanotai described herein and also other abundant cirratulids in the same lower slope depths. Like $C$. brunnea, $C$. spinosa is most abundant at the deepest stations (2700-2850 m).

Distribution. Off Japan, $280 \mathrm{~m}$; off California, ca. 2000-3100 m.

\section{DISCUSSION}

The Cirratulidae represent one of the most speciose families among the Polychaeta, yet the species along many coastlines are poorly known. Frequently, names commonly applied to local species are derived from European works such as Fauvel (1927). As part of a review of the family, 


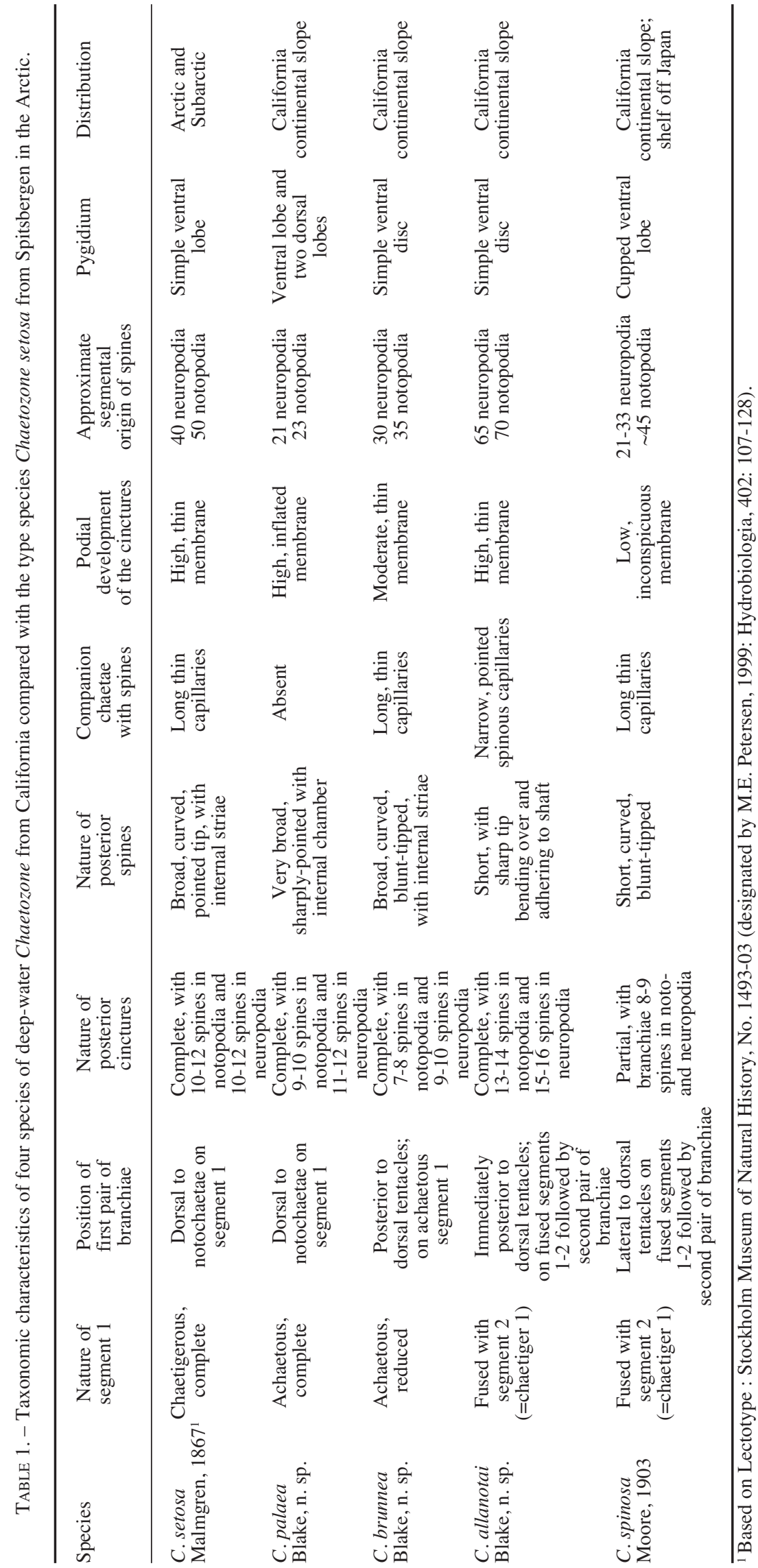

Blake (1996) described 46 cirratulids from the eastern Pacific continental shelf and intertidal zones, mostly from California. Of these, 20 were new to science. Blake (1996) suggested that few cirratulid species were widely distributed. Numerous species were discovered that were associated with local habitats or specific sedimentary conditions. This pattern now appears to be worldwide. Companion studies of cirratulids from Antarctica and along the eastern North American shelf and slope reveal endemic and largely undescribed cirratulid faunas. New cirratulids have been recently described from the northeastern Atlantic (Chambers, 2000; Chambers and Woodham, 2003). Three new species of Chaetozone and one new species of Caulleriella from off Massachusetts in relatively shallow depths are described as part of a companion paper in this volume (Doner and Blake, 2006). A monograph on Antarctic cirratulids is being written (Blake, in preparation). A study of Central American cirratulids has yielded more than 20 new species (Dean and Blake, in preparation). The three new species of Chaetozone described in the present paper represent the first effort to describe the rich cirratulid fauna from deep water off California.

Table 1 presents comparative data on the four species of Chaetozone from SF-DODS off California compared with observations on the lectotype of C. setosa, the type species. Comparison with C. setosa is necessary because so many species have been erroneously referred to that taxon. Each of the four California species differs from C. setosa in combinations of characters, suggesting that when data from other Chaetozone species is 
compiled that several distinct species groups will be apparent. The most obvious feature is associated with the placement of the tentacles and first pair of branchiae. In some species, such as C.allanotai, the first branchiae are located directly behind the tentacles. In other species, such as C. palaea, the first pair of branchiae are situated more posteriorly on a separate achaetous segment. This latter arrangement is also found on C. setosa. A somewhat intermediate condition exists for $C$. brunnea, in which the achaetous segment is reduced and the branchiae are shifted to a position closer to the tentacles. Study of the segmental and anterior branchial patterns on these new species and on other species such as those described by Blake (1996) suggests that the different positions of the first pair of branchiae are caused by the degree to which segment 1 is reduced. For example, in $C$. allanotai and $C$. spinosa, the achaetous segment 1 is greatly reduced as follows: (1) in $C$. allanotai the achaetous segment is entirely lost with the branchiae being incorporated into chaetiger 1 (=segment 2); (2) in C. spinosa the branchiae are present on a much reduced first segment. These observations may have relevance in developing a phylogenetic analysis of cirratulids.

Other characters of importance for Chaetozone include the presence, structure, and arrangement of the posterior spines for which there is a full range of development. The structure of the major noto- and neuropodial spines is highly variable. In C. palaea, they are very broad and hollow internally. In $C$. setosa and $C$. brunnea they are narrower, blunttipped, and may have internal striae. In C. allanotai, the spines are narrow with a fine tip curving over and fusing with the shaft (seen with light microscopy, but obscured with SEM). This same type of seta occurs in C. commonalis Blake, 1996 California shelf depths, C. curvata HartmannSchröder, 1965 from off Chile, and a new species from New England (Doner and Blake, 2006). In $C$. lunula Blake (1996) from California shelf depths and a new species from off New England being described by Doner and Blake (2006) in this issue, there are bifid spines among the unidentate spines. The presence of bifid spines is reminiscent of species of Caulleriella Chamberlin, 1919. However, Caulleriella is a very distinctive genus having widely separated noto- and neuropodia in addition to bifid hooks and capillaries; spines are lacking in Caulleriella (Blake, 1996). Companion chaetae in the posterior cinctures may be absent as in $C$. palaea, thin capillaries as in C. setosa, and thickened, spinous capillaries as in C. brunnea. Among species reported in this paper, the posterior cinctures of spines are best developed in C. palaea and least developed in $C$. spinosa. It is noteworthy, however, that although the posterior cinctures of $C$. palaea are among the most modified of Chaetozone species, the fully developed achaetous segment 1 and position of the first branchiae are among the least modified. Contrast this arrangement with that of $C$. allanotai in which the achaetous segment is much reduced and the branchiae are thus positioned immediately behind the tentacles. Clearly, modification of different characters and regions of the body differ among the various groups of Chaetozone species.

The position and nature of the nuchal organ may also be an important character. Nuchal organs may also be pigmented. For example, deeply pigmented "eyes" reported originally for Chaetozone corona Berkeley and Berkeley (1941) and later by Hartman (1961; 1969) and Blake (1996) are actually pigmented nuchal organs (Dean and Blake, in preparation). The present study also suggests that modifications to the digestive tract and the formation of spherical faecal pellets as seen in C. brunnea may also serve as useful characters. All of these characters and others such as modifications to the peristomium, parapodia, and pygidium will eventually be coded as part of a monograph and phylogenetic analysis of Chaetozone and closely related cirratulids.

From an ecological basis, Chaetozone brunnea, C. allanotai, and C. spinosa, in order, are important components of benthic communities at SF-DODS and the middle and lower continental slope off northern California. The first two species are relatively small, but $C$. spinosa is a large, robust species that contributes significantly to the overall biomass of benthic communities at SF-DODS.

\section{ACKNOWLEDGEMENTS}

The 1990 and 1991 baseline surveys were supported by the U.S. Navy and U.S. EPA Region IX (USEPA), San Francisco. The U.S. EPA and U.S. Army Corps of Engineers (USACE) in San Francisco provided support for collection and analysis of samples during the SF-DODS monitoring surveys. I thank Mr. Allan Ota of the USEPA and Mr. Mike Donnelly of the USACE for their support and 
encouragement. Support in the field from my colleagues Pamela Arnofsky Neubert, Isabelle P. Williams, Russ Winchell, and Howard Jones in the most recent surveys and George Hampson, Rob Williams, and Brigitte Hilbig in the earlier surveys was critical in obtaining well-preserved specimens for study. The officers and crew of the R/V Point Sur of Moss Landing, California are thanked for excellent navigation and sample deployment support. Mr. Hovey Clifford of the Woods Hole Oceanographic Institution is thanked for expertly preparing the box cores that are used to collect the samples. This study was supported by the National Science Foundation under Grant No. DEB-0118693 (PEET) to James A. Blake, University of Massachusetts, Boston.

\section{REFERENCES}

Berkeley, E. and C. Berkeley. - 1941. On a collection of Polychaeta from southern California. Bull. Sth. Calif. Acad. Sci., 40: 16-60.

Blake, J.A. - 1996. Chapter 8. Family Cirratulidae. In: J.A. Blake B. Hilbig and P.H. Scott (eds.), Taxonomic Atlas of the Santa Maria Basin and Western Santa Barbara Channel. Vol. 6. Annelida Part 3. Polychaeta: Orbiniidae to Cossuridae, pp, 263-384. Santa Barbara Museum of Natural History, California
Chambers, S.J. - 2000. A redescription of Chaetozone setosa Malmgren, 1867 including a definition of the genus, and a description of a new species of Chaetozone (Polychaeta: Cirratulidae) from the northeast Atlantic. Bull. Mar. Sci., 67: 587-596.

Chambers, S.J. and A. Woodham. - 2003. A new species of Chaetozone (Polychaeta: Cirratulidae) from deep water in the northeast Atlantic, with comments on the diversity of the genus in cold northern waters. Hydrobiologia, 496: 41-48.

Doner, S.A. and J.A. Blake. - 2006. New species of Cirratulidae (Polychaeta) from the northeastern United States. Sci. Mar., 70S3: 65-73.

Fauvel, P. - 1927. Polychètes sédentaires. Addenda aux errantes, archiannélides, myzostomaires. Faune de France, 16: 1-494.

Hartman, O. - 1961. Polychaetous annelids from California. Allan Hancock Pac. Exped., 22: 1-226.

Hartman, O. - 1969. Atlas of the Sedentariate Polychaetous Annelids from California. Allan Hancock Foundation, University of California, Los Angeles.

Hartmann-Schröder, G. - 1965. Die Polychaeten des Eulitorals. In: Hartmann-Schröder, G. und G. Hartmann, Zur Kenntnis des Eulitorals der chilenischen Pazifkküste und der argentinischen Küste Südpatagoniens uner besonderer Berücksichtigung der Polychaeten und Ostracoden. Mitt. Hamb. Zool. Mus. Inst. Suppl., 60: 57-167.

Imajima, M. and O. Hartman. - 1964. The polychaetous annelids of Japan. I-II. Allan Hancock Found., Occ. Pap., 26:1-452, 38 pls.

Moore, J.P. - 1903. Polychaeta from the coastal slope of Japan and from Kamchatka and the Bering Sea. Proc. Phil. Acad. Nat. Sci., 55: 401-490, pls 23-27.

Petersen, M.E. - 1999. Reproduction and development in Cirratulidae (Annelida: Polychaeta). Hydrobiologia, 402: 107-128.

Received September 15, 2004. Accepted May 11, 2005. 
